\title{
Classification and improvement of the flow condition with spatial distribution in unsaturated soil
}

\author{
Mari Sato ${ }^{1}$
}

Received: 12 April 2020 / Accepted: 30 July 2020 / Published online: 15 August 2020

(C) The Author(s) 2020Abstract

Seepage flow in unsaturated soil cannot be accurately calculated or measured using existing theories, as they consider several assumptions, and associated simulations are conducted under ideal conditions. Exact values such as velocity and pressure inside the unsaturated ground are not obvious that are often estimated by the seepage flow analysis. Those estimated values are not often corresponded to the measured values well. This study aimed to re-evaluate the conditions that well-known theories are established without any failures and aim to reduce the inconsistency for numerical analysis. Concretely, it develops a simple method to judge the inconsistency of well-known theories on geotechnical engineering in unsaturated soil by utilizing the fundamental magnitude relations of several properties and velocity terms in Bernoulli's principle. As a result, consistent and inconsistent conditions are classified, although it is estimated that continuous seepage ranges close to the piezometric head conservation equation: $h=z+\psi$. The classification by this judgement is contributed to the estimation of the ground seepage condition using the combination of pressure head and hydraulic head difference in practical sites. Moreover, the inconsistency can be solved by assuming the local hydraulic gradient distributions. The hydraulic gradient modification is proposed by installing tentative seepage length and tentative hydraulic head for flow analysis. Finally, the local hydraulic gradient led by the proposed equations is calculated with the Mualem-van Genuchten model; the calculation results show the modified local hydraulic gradient is valid and applicable. Future works include discretization and analytical method. The criterion can immediately judge whether ground conditions and modification methods can be used for a more accurate seepage analysis in unsaturated soil.

Keywords Unsaturated $\cdot$ Judgement criteria $\cdot$ Bernoulli's principle $\cdot$ Numerical analysis $\cdot$ Water content

\section{Introduction}

Despite a recently conducted numerical analysis, the seepage situation inside the ground cannot be precisely measured in practical sites. In ground disasters, for example, as in case of sudden rainfall, most ground areas are unsaturated. Even though in situ investigation and monitoring has improved, estimating the ground condition by monitoring remains a challenge. Numerous studies related to the prevention of disasters of earth structures due to seepage, such as field monitoring

\section{Responsible Editor: Broder J. Merkel}

This paper was selected from the 2nd Conference of the Arabian Journal of Geosciences (CAJG), Tunisia 2019

Mari Sato

maris@life.shimane-u.ac.jp; msatolasperanza@gmail.com

1 Academic Assembly, Shimane University, Matsue, Japan and large-scale experimentation (e.g., Tu et al. (2009) and Fazlina et al. (2018)), exist. Consolidation is another problem, e.g., Kassou et al. (2020), and a soil improvement method has been evaluated by Emeka et al. (2018). The seepage in practical sites exhibits a very complicated behavior, and sometimes the analytical assumptions are not satisfied. Especially, ground parameters such as hydraulic gradient/pressure, moisture content, and flow velocity are only estimated by the numerical analysis and monitored by the limited number of sensors. This study first evaluated the momentary conditions that satisfy well-known theories of the unsaturated soil in two points along vertical flow. The derivation of the criterion applies the Bernoulli's principle, serving as an energy law, the magnitude relations commonly known as unsaturated soil theories, and Darcy's law (Darcy 1856). Though the velocity term $v^{2} \approx 0$ in Bernoulli's principle is assumed in soil, this study concerns the velocity term as it is. A situation is considered wherein these relations are not met, and the calculations are not performed completely. It is calculated as a one- 
dimensional vertical flow, revealing that there are several situations where the continuous flow cannot be established under the well-known principles of unsaturated soil. The condition is known as an inconsistent condition in this study. The opposite is known as a consistent condition. The criterion is simply governed by the gaps of matric suction and hydraulic head between two points and has the advantage in that the criterion can be easily and immediately applied and the ground seepage condition can be estimated only by the measurement of two points, In addition, the well-known theory does not need to be changed. The proposed study uses very simple unsaturated soil theories, but the unsaturated soil behavior is complicated and there are numerous previous studies to deal with the complexity;. its micro scale modeling and analysis have been developed under various conditions (e.g., Scott and Dani (1999), Mohammad and Martin (2005), and Wulong et al. (2018)). On the other hand, seepage analysis by discretization through finite element method, FEM, is the most prevalent approach for designing structures and research even though other analysis methods have been developed such as SPH, e.g., Bui and Nguyen (2017). Algorithms and schemes have been developed over extensive time periods (e.g., Huyakorn et al. 1984, 1986)). Various commercial software such as ABAQUS, reffering to Fish and Belytschko (2007) and Abaqus analysis user guide 6.14, are broadly applied for analyses under various situations. The algorithms are primarily based on Richard's equation (Richards 1931); the study also discusses the conditions surrounding the equation. One of the reasons for a difference between numerical analysis and experimental/investigated data can be attributed to the local variations, such as density and water content, found in the practical soil. Recently, the evaluation methods regarding this uncertainly are proposed for the soil properties related to the seepage analysis, e.g., Baecher and Christian (2003), and Shishido et al. (2018). A few previous studies have been conducted in the aforementioned fields about the inconsistency among known- theories; Whitaker (1986) presented spatial derivation of Darcy's Law by the volume averaging theory, reevaluating the known theories. Wagner and Gorelick (1989) applied the stochastic inverse model to the local hydraulic conductivity and head data, which is applied to FEM analysis. Ye et al. (2009) introduced a heuristic computing method for local hydraulic conductivity of the gas flow. In addition, there are some studies intended to modify the theoretical value on the unsaturated flow modeling by using the simple investigated data, such as, Chong et al. (1981), Sisson (1987), and McCord (1991). Most of those methods require in situ data being superior at the particular investigated sites. This study's subsequent goal is the proposal of a simpler method that corrects the differences among numerical analysis, experiments, and site investigations without in situ data by the application of common theories. In the derived criterion, the vicinity of the standard piezometric head conservation law of unsaturated soil $\mathrm{h}=\psi+\mathrm{z}$ referring to Richards (1931) is focused on, which has the possibility for generating continuous flow under the inconsistent condition because most of the inconsistent condition in the criterion is caused by a sudden change of flow conditions or pressures, and continuous flow is not fulfilled under that condition. A hypothesis, wherein the hydraulic gradient is locally changed under the inconsistent condition close to the standard energetic conservation, is formulated. The proposal considers the modification of the hydraulic gradient distribution. The local hydraulic gradient is known to induce collapse as piping erosion or suffusion. These phenomena are not directly related to the study, but there are several investigations and experiments that find and discuss the piping phenomenon, e.g., Jones (1971), Moffat et al. (2011), and Van Beek et al. (2015). In addition, numerical analysis has been developed, e.g., Tao and Tao (2017).

Finally, the specific values derived from this proposed criterion and a modification method are calculated with the Mualemvan Genuchten model. It revealed that the modified value is appropriate, and a proposed modification method may be applicable to the FEM analysis, when the ground condition is defined as inconsistent in the above-mentioned criterion, and it will beneficial to the accurate flow analysis of the unsaturated soils. The future work will involve discretization, e.g., Hughes (1987) and Ho-Le (1988) and the adoption of a numerical analysis. This proposal contributes to alleviate the situations wherein the broadly known theories have not been completely established, and intends to estimate more stringent situations of ground seepage without new theories or field data.

The paper first describes about the preconditions and applied equations. The criterion is derived and classifies consistency and inconsistency based on the applied equations. Then, these two conditions are discussed and modification of hydraulic gradient is proposed for reducing inconsistency in known theories. Finally, the specific values are derived from the modification method that reveals the proposed method is applicable for numerical analysis. The flowchart of the paper's structure is illustrated in Fig. 1.

\section{Preconditions and equations}

The vertical flow is estimated between two points called point 1 and point 2 in a small element as shown in Fig. 2. The pressure, velocity, and height for point $n$ are denoted by $P_{n}, V_{n}$, and $z_{n}$, respectively. Bernoulli's principle is given as Eq. (1),

$\frac{1}{2} v_{1}^{2}+\frac{P_{1}}{\rho}+g z_{1}=\frac{1}{2} v_{2}^{2}+\frac{P_{2}}{\rho}+g z_{2}+g h_{12}$.

Here, $h_{12}$ is the hydraulic head loss from point 1 to point 2 , and $P / \rho g$ is $\psi$, which is the pressure head. The pressure head has a negative value in unsaturated soil. In geotechnical 


\begin{tabular}{|c|c|}
\hline $\begin{array}{l}\text { [Preconditions] Vertical flow between two points are calculated } \\
\text { in unsaturated soil base on Bernulli's principle and Darcy law }\end{array}$ & Chapter 2 \\
\hline $\begin{array}{l}\text { [Assumptions and Calculattion] Known theories are installed } \\
\text { and judged whether positive/ negative of each symbols are } \\
\text { established without any failures. }\end{array}$ & $\zeta 3.1$ in Chapter 3 \\
\hline $\begin{array}{l}\text { [Results] The equation is lead from the abovementioned } \\
\text { assumptions and equation. The equation, known as judgement } \\
\text { criterion is proposed in this study. It is applicable at a certain } \\
\text { ranges of water content. } \\
\text { By the use of the equation, the ground situation is theoretically } \\
\text { separated by two conditions; establishing this equation is } \\
\text { known as consistent and if not established, it is known as } \\
\text { inconsistent. }\end{array}$ & -3.2 and 3.3 in Chapter 3 \\
\hline $\begin{array}{l}\text { [Discussion1] The judgement and two conditions are only } \\
\text { theoretically calculated in Results, followed by a discussion of } \\
\text { each condition's details. In addition, a discussion follows of a } \\
\text { situation which is unlikely to occur in practical ground and the } \\
\text { criterion usage limitations }\end{array}$ & $\zeta$ From 4.1 to 4.3 in Chapter 4 \\
\hline $\begin{array}{l}\text { [Discussion 2] Application to numerical analysis] Discussion } \\
\text { reveals that the localized hydraulic gradient should be more } \\
\text { considered at an inconsistent condition, and then a simple } \\
\text { application method is proposed. Finally, the specific values } \\
\text { derived from the proposed application method are calculated } \\
\text { on typical soils with the Mualem-van Genuchten model. }\end{array}$ & $\leftarrow 4.4$ in Chapter 4 and Chapter 5 \\
\hline
\end{tabular}

Fig. 1 Flowchart of the proposed study

engineering, the absolute value of the pressure head is known as matric suction. Note that this paper applies the pressure head rather than matric suction for the simplicity of calculations. The soils between points 1 and 2 are estimated to be of uniform materials with equal porosity, cross-sectional area, and fluid density $\rho$. Volumetric water content of each point is denoted by $\theta_{n}$ and Darcy's law is applied,

$v_{n}=\frac{k^{s} K_{r}\left(\theta_{n}\right)}{\theta_{n}} \frac{d h}{d z}$, where $k^{s}$ is the saturated hydraulic conductivity assumed to be constant among two points and $d h / d z$ is the hydraulic gradient at point $n$. Equation (2) indicates that the Darcy velocity is translated to the true flow velocity in voids, represented as $v_{n} . K_{r}(\theta)$ is the relative permeability coefficient and a function of $\theta$. Permeability coefficient $k$ is calculated by $k^{s} K_{r}\left(\theta_{n}\right)$. When the soil is saturated, $K_{r}\left(\theta_{n}\right)$ is equal to 1 and the volmetric water content at saturation is represented as $\theta_{s}$ in Fig. 3. Equation (1) is transformed to the following equation; note that point 1 is higher than point 2 in height: $\Delta z>0$. The upward direction is defined as positive. Note
Fig. 2 Symbols of onedimensional seepage flow

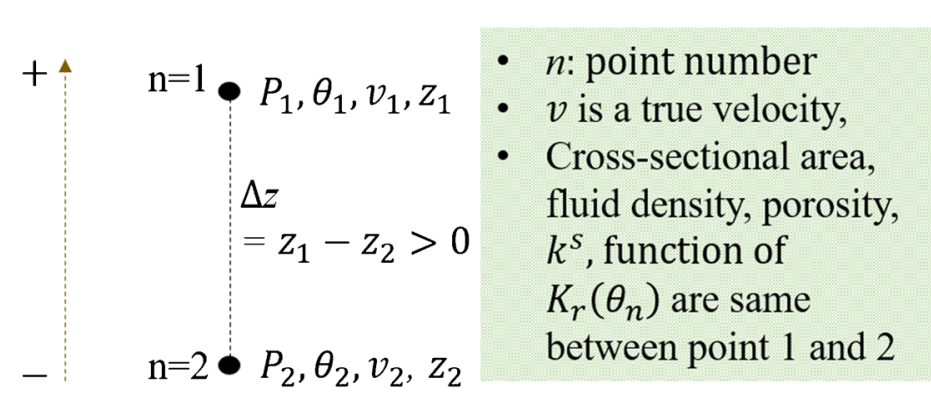

[flow direction]

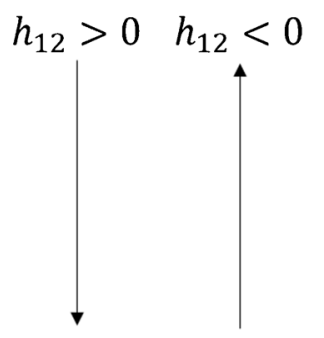


that the positive and negative of hydraulic head loss is opposite to the generated flow direction by that (see Fig. 2). Equation (1) is the common form of Bernoulli's principle and is transformed to Eqs. (3a) to (3c) here,

$$
\begin{aligned}
& \frac{1}{2 g}\left(v_{1}^{2}-v_{2}^{2}\right)=-\frac{\Delta P}{\rho g}-\Delta z+h, h=h_{12}, \\
& \Delta P=P_{1}-P_{2}, \\
& \Delta z=z_{1}-z_{2}=\text { const. }>0
\end{aligned}
$$

These concepts of equations and preconditions are commonly used in geotechnical engineering, e.g., Bear (1972). The velocity term has not been considered for calculations as it is negligibly small when compared to the other terms. This study uses the velocity term for judging the flow and fulfills the known relations in unsaturated soil out of precise calculations.

\section{Evaluation of the stability of unsaturated flow}

\section{Classification of consistent or inconsistent based on the theories}

In this study, the following conditions are defined to be necessary for consistency under the theories of unsaturated soil:

(i) The magnitude relations between permeability, pressure head, and water content are established as shown in Fig. 3: Pressure head and relative permeability coefficient are increased owing to an increase in water content $\left(\partial \psi / \partial \theta>0, \partial K_{r} / \partial \theta>0\right)$. Note that $k^{S}=$ const.

(ii) Localized hydraulic gradient and flow direction are equal to their averaged values through the points: $d h / d z=$ const. for the entire portion, and $v_{1} v_{2}>0$.

(iii) The direction of the entire hydraulic head loss $h$ corresponds to the direction of velocity: $v_{1}+v_{2}<0$ if $h>0$, downward and $v_{1}+v_{2}>0$ if $h<0$, upward.

(iv) Pressure head $\psi$ is always negative in unsaturated soil.

These conditions are well known in geotechnical engineering, and the study solves consistency by adding a fifth condition, based on condition (i).

(v) The true velocity applied to Darcy's law, given in Eq. (2), is satisfied. The condition assumed is that Eqs. (4a) and (4b) are satisfied based on previous experimental studies and models, e.g., Childs and Collis-George 1950, and van Genuchten (1980). It is also assumed $\theta_{1}$ and $\theta_{2}$ are not significantly different from each other. This represents the range in which the magnitude relation of the absolute value of true velocity inside the fluid porosity is equal to

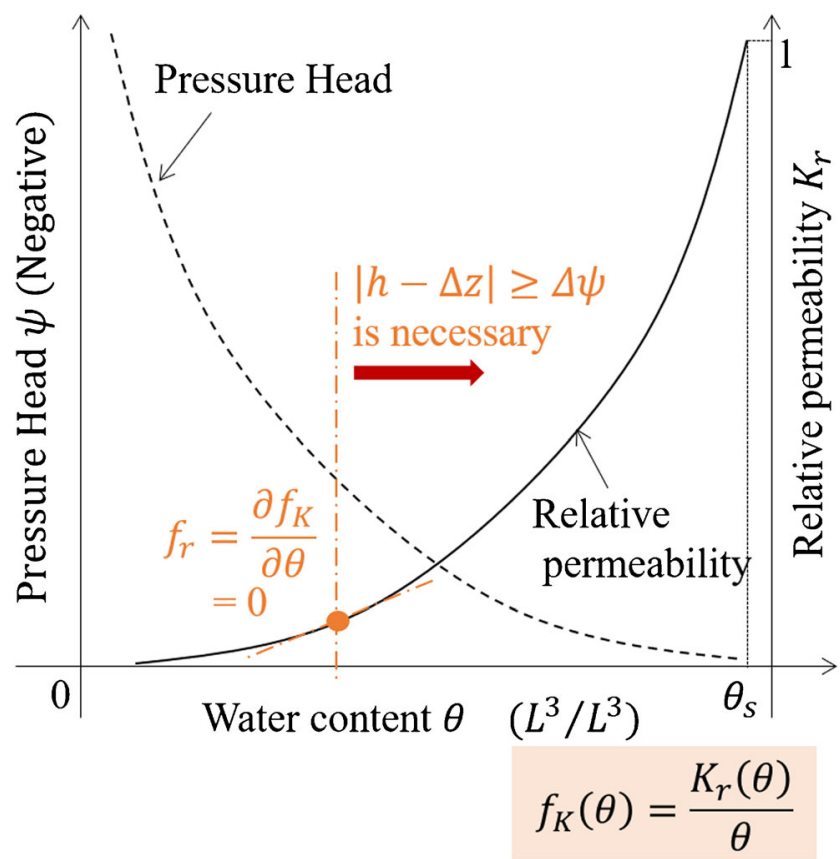

Fig. 3 Relationships between $\psi, K_{r}$, and $\theta$ and schematically gradient

the relation of the absolute value of Darcy's velocity when the hydraulic gradient is constant,

$f_{K}(\theta)=\frac{K_{r}(\theta)}{\theta}$,

$\frac{\partial f_{K}(\theta)}{\partial \theta} \geq 0 \Rightarrow\left(\frac{K_{r}\left(\theta_{1}\right)}{\theta_{1}}-\frac{K_{r}\left(\theta_{2}\right)}{\theta_{2}}\right)\left(\theta_{1}-\theta_{2}\right) \geq 0$.

The gradient of permeability is known to gradually increase due to the increase in water content, as shown in Fig. 3. $k^{s}$ is constant throughout the points; the change of $K_{r}(\theta)$ is considered. Equation (4) is satisfied within a range of certain water content. The case not satisfied by the equation is described in Sections 3.3 and 4.3. Permeability coefficient $k\left(\theta_{n}\right)$ is related to the pressure, $P_{n}=\psi_{n} \rho g$, and a few models and experiments (e.g., Childs and Collis-George (1950); Brooks and Corey (1966), Mualem (1976) and van Genuchten (1980)) have already proposed the relations among them. This research shows the simple relationships between negative pressure head/matric suction and water content as follows. In brief, Eq. (5) indicates that the pressure head increases and the matric suction decreases when water content increases (see condition (i)),

$\frac{\partial \psi}{\partial \theta} \geq 0$

Based on the five conditions (i) to (v) mentioned, along with Eqs. (2) to (5), the terms of Bernoulli's principle are judged on whether the principle is entirely established without any failures. Failures are considered only by the positive or negative of every 
term, as shown in Table 1. The cases without failures are called consistent. Positive or negative values of each symbol are fixed in cases as shown in Table 1, and a few symbols are related to each other as represented in Eq. (3). Subsequently, each case is judged on, whether every fixed assumption is established.

\section{Simple judgement of consistency for the theories of unsaturated flow}

Only those cases italicized in Table $1, \mathrm{~Pa}, \mathrm{Na}$, and $\mathrm{Nb}$, satisfy the consistency in this study and are summarized as Eq. (6) and Fig. 4; these cases are known as consistent conditions, while the others are known as inconsistent. The classification of (I) and (II) for consistent/inconsistent in the figure is described in the following chapter,

$|\mathrm{h}-\Delta \mathrm{z}| \geq \Delta \psi, \quad \Delta \psi=\Delta P / \rho g$,

where $\Delta \psi$ is the gap of the pressure head between point 1 and point 2. If matric suction is applied instead of pressure head, $-\Delta P / \rho g$ can be used as the matric suction,

$\mathrm{h}-\Delta \mathrm{z}=\Delta \psi$, under $\mathrm{v}^{2} \approx 0$ or $\mathrm{v}_{1}=\mathrm{v}_{2}$

The boundaries of consistent and inconsistent zones are shown in Eq. (7), which determines the spatial gap of piezometric head conservation: $\psi_{\mathrm{n}}=\mathrm{H}_{\mathrm{n}}-\mathrm{z}_{\mathrm{n}}$, between two points: $n$ is the point number and $\mathrm{H}_{\mathrm{n}}$ is the total hydraulic head. This conservation is used in various numerical models along the vertical direction, in the case of neglecting the velocity term of the energy law. Equation (7) is known as piezometric head line in the study. The equation indicates that the pressure head determines the hydraulic gradient, and water is submerged due to the negative pressure head, suction. Though $\Delta \psi$ is supposed to be very close to the line of $\mathrm{h}-\Delta \mathrm{z}$ in the permanent flow as subsequently explained, the figure is illustrated by Eqs. (6) and (7). In the subsequent sections, the details of consistent or inconsistent conditions are discussed by the classification of (I) and (II), respectively.
Application range of the proposed classification on water content

This criterion is not met in a water content zone, ranging $\frac{\partial f_{K}(\theta)}{\partial \theta}$ $<0$ in Eq. (4). This zone is generally estimated in a lower water content zone, where the increase in the relative permeability along with that of water content is not significant. When $\frac{\partial f_{K}(\theta)}{\partial \theta}<0$, the judgement of consistency is reversed; an inconsistent flow condition by Eq. (6) changes to consistent in the proposed manner and consistent flow changes to inconsistent, because $\left(\left|v_{1}\right|-\left|v_{2}\right|\right)\left(\theta_{1}-\theta_{2}\right) \leq 0$ is fulfilled for this range. This study defines function $f_{r}$ for judging the application of the criterion as shown in Eq. (8) for the simplicity of the explanation,

$f_{r}=\frac{\partial f_{K}(\theta)}{\partial \theta}$

The criterion given in Eq. (6) should be considered, when $f_{r} \geq 0$. When $f_{r}<0$, the proposed criterion cannot be applied and the judgement reverses. However, a broad range of water content and several materials fulfill $\mathrm{f}_{\mathrm{r}}>0$, and the situation fulfilling $\mathrm{f}_{\mathrm{r}} \leq 0$ is supposed to be limited. The values of $\mathrm{f}_{\mathrm{r}}$ with standard materials are demonstrated in Chapter 5.

\section{Discussion}

Consistent and inconsistent zones depicted by Eqs. (6) and (7) are separated to certain extent as shown in Fig. 4. The conditions of each zone are described in the following sections.

\section{Consistent condition}

Equation (3a) is translated to Eq. (9),

$\frac{1}{2 g}\left(v_{1}^{2}-v_{2}^{2}\right)+\Delta \psi=h-\Delta z, h=h_{12}$

Table 1 Classification of judged cases of stable conditions

\begin{tabular}{|c|c|c|c|c|c|}
\hline Case & $\frac{1}{2 g}\left(v_{1-}^{2} v_{2}^{2}\right)$ & $-\Delta z-\frac{\Delta P}{\rho g}+h$ & $h-\Delta z$ & $\frac{\Delta P}{\rho g}$ & $h$ \\
\hline $\mathrm{Pa}$ & $>0$ & $>0$ & $>0$ & $>0$ & $>\Delta z>0$ \\
\hline $\mathrm{Pb}$ & $>0$ & $>0$ & $>0$ & $<0$ & $>\Delta z>0$ \\
\hline $\mathrm{Pc}$ & $>0$ & $>0$ & $<0$ & $<0$ & $\Delta z>h>0$ \\
\hline $\mathrm{Pd}$ & $>0$ & $>0$ & $<0$ & $<0$ & $<0$ \\
\hline $\mathrm{Na}$ & $<0$ & $<0$ & $<0$ & $<0$ & $\Delta z>h>0$ \\
\hline$N b$ & $<0$ & $<0$ & $<0$ & $<0$ & $<0$ \\
\hline $\mathrm{Nc}$ & $<0$ & $<0$ & $>0$ & $>0$ & $>\Delta z>0$ \\
\hline $\mathrm{Nd}$ & $<0$ & $<0$ & $<0$ & $>0$ & $\Delta z>h>0$ \\
\hline $\mathrm{Ne}$ & $<0$ & $<0$ & $<0$ & $>0$ & $<0$ \\
\hline
\end{tabular}


Fig. 4 Boundaries of consistency under known theories among $h$, $\Delta z$ and $\Delta \psi$

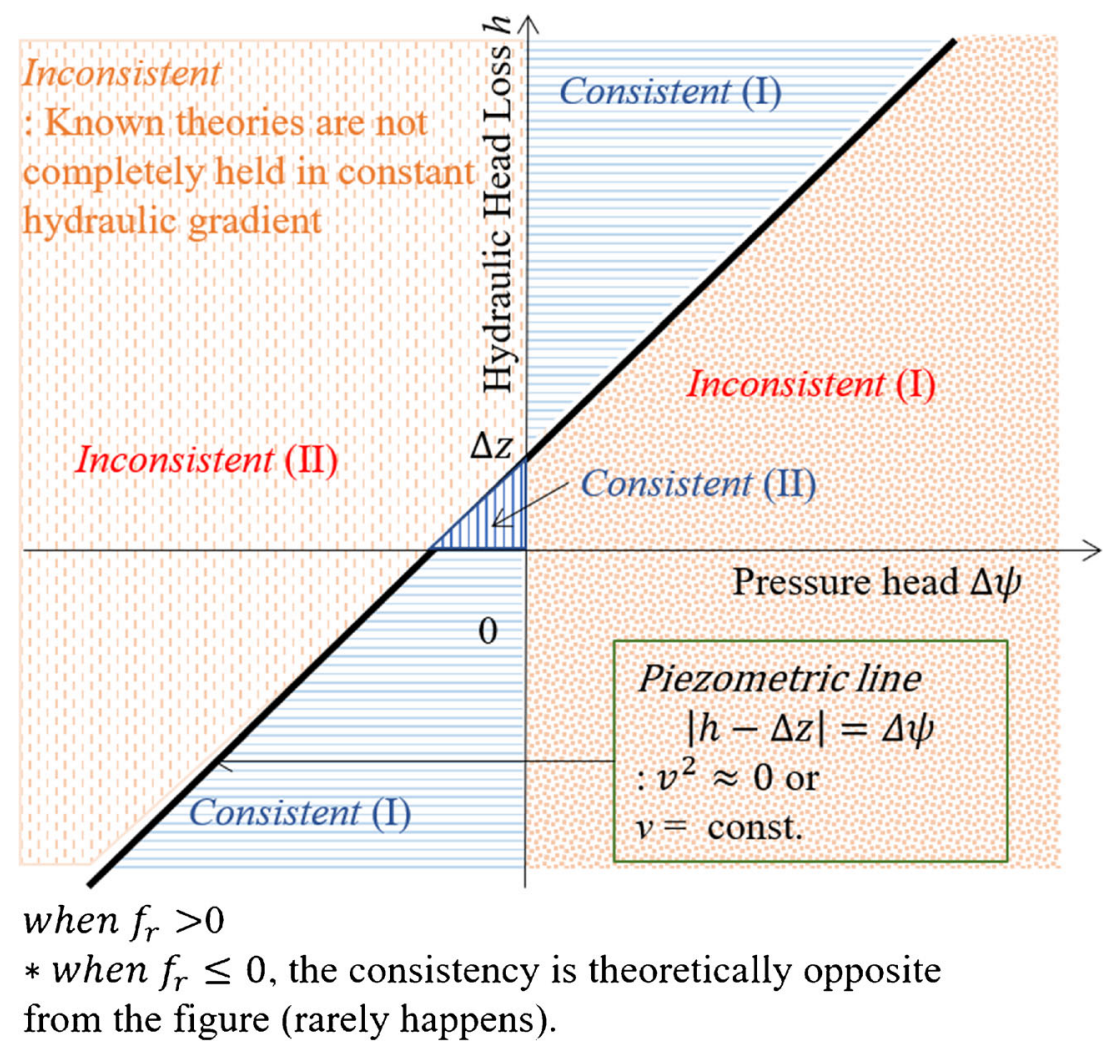

Ranging in the consistent condition (I), the water flows from a wetter portion to a drier one with a larger velocity in the wetter portion, given by the term of $v_{1}^{2}-v_{2}^{2}$, and storage is promoted as discussed in 4.2. The flow direction is unique in the consistent condition (II). The water penetrates from a drier, upper portion to a wetter, lower portion, although it is limited when the spatial gap of suction and pressure head between two points is very small. This phenomenon might easily occur from the condition wherein the pressure head gap is equal to the distance between the two points, and the head loss is zero with no regular flow conditions.

The actual range where the continuous flow happening is estimated to be very close to the piezometric head line of Eq. (7) as mentioned previously, as $v_{1}^{2}-v_{2}^{2}$ of the velocity term is small compared to other terms. The zones far from the piezometric head line under the consistent condition indicate that the head loss is much larger than the pressure head gap of the ground. The velocity term is very small for the soil, and the energy conservation law of Bernoulli's principle is not satisfied throughout the specimen. If that is intentionally generated, the collapse might have occurred by the consumption of significant energy by the hydraulic head.

\section{Inconsistent condition}

When the cases do not satisfy Eq. (6), it can be assumed that the fixed negative or positive of the velocity term do not correspond to those derived from the pressure head term. The reason is estimated as follows; (a) $K_{r}\left(\theta_{n}\right)$ or (b) $d h / d \mathrm{z}$, is mistakenly evaluated, or (c) the localized velocity $v_{n}$ has a different direction from that led by the head loss, h. The measurement method of hydraulic conductivity of $K_{r}\left(\theta_{n}\right)$ has been studied extensively, e.g., Richard and Moore (1952), and Klute (1965), and improved by Schindler et al. (2010). Those research measures $K_{r}\left(\theta_{n}\right)$ after the entire specimen become a time-invariant condition, being close to the piezometric head line in Fig. 4 for awaiting constant pressure head and flow rate. Therefore, the values of $K_{r}\left(\theta_{n}\right)$ are assumed to be appropriate. The localized velocity $v_{n}$ has a different direction from that of h, which is not realistic for items such as smallscale modeling. Therefore, it is considered that the localized hydraulic gradient is not constant. This study formulates a hypothesis that Eq. (10) is fulfilled in a consistent condition but it is not fulfilled in an inconsistent condition because of the value of $\mathrm{dh} / \mathrm{dz}$. Please note that its assumed direction of flow in each point is the same; $v_{1} v_{2}>0$ in condition (ii) as described in Section 3.1,

$\left(\left|v_{1}-v_{2}\right|\right)\left(\theta_{1}-\theta_{2}\right) \equiv\left(\left|\frac{K_{r}\left(\theta_{1}\right)}{\theta_{1}} \frac{d h}{d z}\right|_{n=1}-\left.\frac{K_{r}\left(\theta_{2}\right)}{\theta_{2}} \frac{d h}{d z}\right|_{n=2} \mid\right)\left(\theta_{1}-\theta_{2}\right)>0$

and $v_{1} v_{2}>0$.

There are two cases for $\theta_{1}>\theta_{2}$, inconsistent condition (I) or $\theta_{1}<\theta_{2}$, inconsistent condition (II), and the former is represented as Eq. (11); the schematic of this condition 
is depicted in Fig. 5a, separated as two patterns: Upward and downward flow.

Note that the case of fulfilling $h<0$ and $\Delta \psi>0$, on the left side of Fig. 5a is far from the piezometric head line, and assumed that it is difficult to generate continuous flow under natural conditions. If it is artificially generated, it might be possible to retain this condition momentarily, but to retain it for longer periods is challenging. In addition, the upper side in a wetter condition is assumed to be challenging because of the gravity force. For the latter case, inconsistent condition (II): $\theta_{2}>\theta_{1}$ can be similarly calculated, which suggests that the drier, higher portion has a larger hydraulic gradient. Under the inconsistent condition (II), Eq. (12) is completed. Figure $5 \mathrm{~b}$ shows the schematic figure; it is just a vertical flip of Fig. 5a. It is noted that the downward flow is limited in the range of small hydraulic head loss: $h \leq \Delta z$ in natural conditions, as only that range is close to the piezometric head line above the consistent (II) as depicted in the left of Fig. 5b. However, the lower part of the wetter portion is natural for the gravity and can possibly occur in the practical ground. Confirming the hypothesis by the experiments in the next step,

$1>\frac{\theta_{1} K_{r}\left(\theta_{2}\right)}{\theta_{2} K_{r}\left(\theta_{1}\right)}>\left.\frac{d h}{d z}\right|_{n=1}\left|\frac{d h}{d z}\right|_{n=2}$, if $\theta_{1}>\theta_{2}$ and $|\mathrm{h}-\Delta \mathrm{z}|<\Delta \psi$,

$1>\frac{\theta_{2} K_{r}\left(\theta_{1}\right)}{\theta_{1} K_{r}\left(\theta_{2}\right)}>\left.\frac{d h}{d z}\right|_{n=2}\left|\frac{d h}{d z}\right|_{n=1}$,if $\theta_{2}>\theta_{1}$ and $|\mathrm{h}-\Delta \mathrm{z}|<\Delta \psi$

Subsequently, the influence on storage is discussed. The situations that can easily occur in practical conditions: The right of Fig. 5a and $\mathrm{b}$ is discussed; the momentary storage $Q$ among the points is represented by Eq. (13). The equation is solved by the assumption that the cross-sectional area is one and absorption is a positive value,

$Q=\left|v_{1} \theta_{1}-v_{2} \theta_{2}\right|=-k^{s}\left[\left.K_{r}\left(\theta_{1}\right) \frac{d h}{d z}\right|_{n=1}-\left.K_{r}\left(\theta_{2}\right) \frac{d h}{d z}\right|_{n=2}\right]$

The relative permeability function $K_{r}(\theta)$ is determined by the experiments and models, and the function of $K_{r}(\theta)$ is similar among point 1 and point 2 as those points consist of same materials and densities. $K_{r}(\theta)$ is larger in the wetter portion but the hydraulic gradient $d h / d z$ is larger in the drier portion. Therefore, the storage $Q$ is predicted to be smaller than the case that does not concern the local hydraulic gradient. Calculation of the specific values is the next step of the study. Please note that this study simulates the momentary condition, and the results of time progression are not valid. Another situation for the left of Fig. 5a and b is reversed to delete the minus sign of Eq. (13), as flow direction is from a drier portion to a wetter portion. The storage might be accelerated compared to right of Fig. $5 \mathrm{a}$ and b. However, the situation rarely happens except of the left of Fig. 5b under under $h \leq \Delta z$ in Eq. (12).
When the condition is far from the piezometric head line similar to the consistent condition, the natural continuous flow is difficult for the lack of satisfaction of Bernoulli's principle as previously mentioned, with a risk of collapse in the drier portion under a high hydraulic gradient similar to the consistent condition. The principle is fulfilled when the continuous flow is generated, and then the flow line can be depicted. The temporary condition is mathematically possible similar to that under the consistent conditions, such as under $\Delta \psi>0$ and $\mathrm{h}$ $<0$, which is the converse between the direction generated by the suction and that by the hydraulic head loss. This situation is not caused by the contentious and natural flow, but the water may be penetrated with high hydraulic head loss and collapse, when the flow is artificially generated. Finally, Fig. 6 depicts the addition of the schematic image of the actual range of continuous flow to Fig. 4. Most of the flows, whether consistent or inconsistent, are under the zones near the analytical piezometric head line momentarily. The gaps with and without considering the local hydraulic gradient may be expanded with time progress and some situations are required to modify from the piezometric head line at the initial state. The following section targets the vicinity zones of analytical piezometric head line and attempt to modify the local hydraulic gradient in inconsistent zones.

\section{Other notable points about $f_{r}$}

This fundamental evaluation proposed a simple criterion that is applicable in the broad range of water content and several soil materials: Under the conditions when $f_{r}>0$ is satisfied. Figure 3 is one of the most common schematic permeability shapes of unsaturated soil, and there are several structured versions, e.g., Todd (1959). The permeability curve shows various types of shapes, and it is predicted that some of the materials have the water content boundary $\theta_{b}$ when $f_{r}==0$. When $\theta>\theta_{b}$ and the soil is relatively wet, the criterion can be applied when the curve is shaped similar to Fig. 3. Generally, coarser materials exhibit a steeper gradient than finer ones, as in Childs and Collis-George (1950); Thus, the proposed criterion is more applicable to coarser materials. However, the permeability measurement of unsaturated soil has various methodologies, and the unsaturated soil has complicated behaviors such as hysteresis curve and air-entry value, as in Fredlund et al. (2012). When the curve and gradient shown in Fig. 3 are not always fulfilled, the proposed criterion can be used, if $f_{r}>0$. The criterion of consistency for the case of $f_{r} \leq 0$ is opposite to $f_{r}>0$, although this study does not discuss the details under this condition. In unsaturated soil, most conditions tend to fulfill $f_{r}>0$. This equation does not simulate the situation at the boundary; one point satisfies $f_{r}>0$ but the other one does not. However, the two points are estimated to be located in a close and continuous condition, and the positive or negative of $f_{r}$ is similar in the two points. 
a
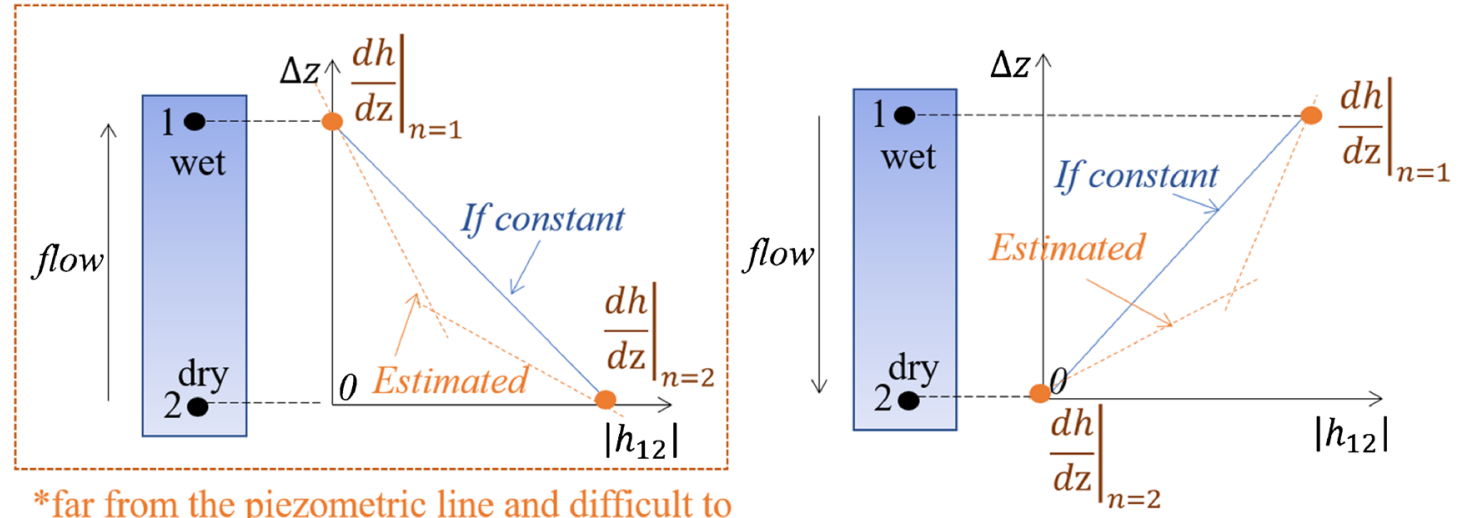

* far from the piezometric line and difficult to generate continuous flow (momentary possible)

b

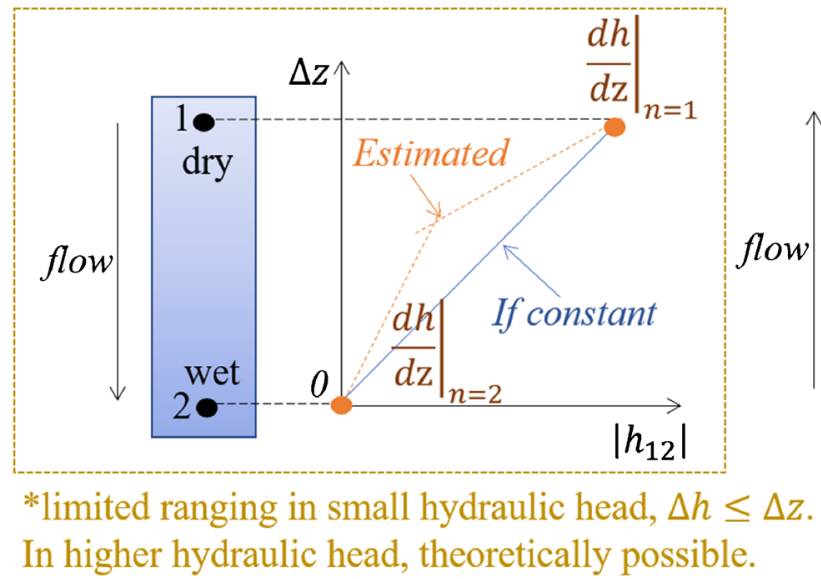

Fig. 5 a Schematic hydraulic gradient line with inconsistent condition when $\theta_{1}>\theta_{2}$. b Schematic hydraulic gradient line with inconsistent condition when $\theta_{2}>\theta_{1}$

\section{Application for numerical analysis}

The velocity term of Bernoulli's principle is estimated to be zero in geotechnical engineering and not exactly zero both for consistent and inconsistent conditions. A few gaps exist from the piezometric head line of Eq. (7). Most existing analysis methods such as FEM and FVM apply the arranged version of Eq. (7) for seepage analysis. They use an approximate solution such as the Method of Weighted Residuals, e.g., Finlyson (1972), and therefore it can be said that Eq. (14) can be solved in real scenarios,

$\mathrm{h}-\Delta \mathrm{z}=\Delta \psi \pm|R|$,

where $|\mathrm{R}|$ is a residual value that remains as the difference from the exact value of conservation of the piezometric head. Therefore, it is assumed that these analyses consider both the consistent and inconsistent conditions close to the piezometric head line. Equation (14) is a momentary situation, and the solved values by analysis are always close to the piezometric head line at a certain moment. However, the differences may gradually extend with time among the cases with or without gaps from the piezometric head line. Especially under the inconsistent condition, the fundamental relations that should be fulfilled are not satisfied, for example, the hydraulic conductivity is smaller with higher water content. Revising the calculation under these conditions is recommended, and the method of modifying the value under the inconsistent condition is proposed herein. It is challenging to use the abovementioned criterion and directly solve it, although the determination of the application is easy and given by Eq. (8): $f_{r}$, if $f_{r} \geq 0$.

For the modification of inconsistent situations, the localized hydraulic gradient is introduced in Eqs. (11) and (12). These equations clarified that the hydraulic gradient is smaller than $\theta_{1} K_{r}\left(\theta_{2}\right) / \theta_{2} K_{r}\left(\theta_{1}\right)$, when $\theta_{1}>\theta_{2}$ and $\theta_{2} K_{r}\left(\theta_{1}\right) / \theta_{1} K_{r}\left(\theta_{2}\right)$, when $\theta_{2}>\theta_{1}$, respectively. Therefore, this section describes the modification methodology of the hydraulic gradient distributions. First, the function of the hydraulic gradient modification $K_{t}\left(\theta_{1}, \theta_{2}\right)$ is introduced as Eq. (15). $\left(\frac{d h}{d z}\right)^{\prime}$ is a modified hydraulic gradient, and the value prime symbol represents that it is modified in the study, 
Fig. 6 Re-arranged Fig. 4 and estimated actual range of continuous flow

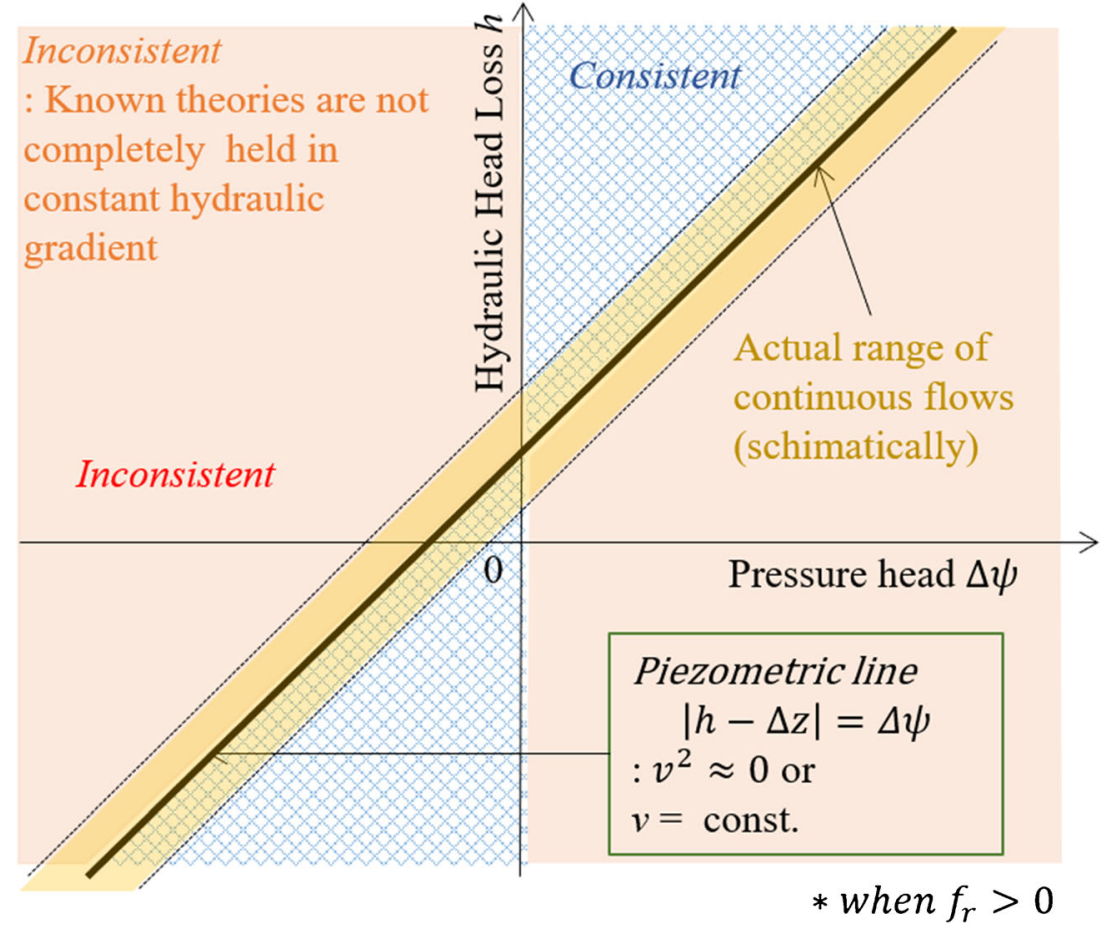

$$
\begin{aligned}
& \frac{\left.\left(\frac{d h}{d z}\right)^{\prime}\right|_{n=1}}{\left.\left(\frac{d h}{d z}\right)^{\prime}\right|_{n=2}}=\frac{\theta_{1} K_{r}\left(\theta_{2}\right)}{\theta_{2} K_{r}\left(\theta_{1}\right)}, \\
& K_{t}\left(\theta_{1}, \theta_{2}\right)=\frac{\theta_{1} K_{r}\left(\theta_{2}\right)}{\theta_{2} K_{r}\left(\theta_{1}\right)}
\end{aligned}
$$

Note that Eq. (15) is the least estimation of the hydraulic gradient difference, as the equation represents the case that right-hand side of Eq. (10): $\left|\frac{K_{r}\left(\theta_{1}\right)}{\theta_{1}} \frac{d h}{d z}\right|_{n=1}-\left.\frac{K_{r}\left(\theta_{2}\right)}{\theta_{2}} \frac{d h}{d z}\right|_{n=2} \mid=0$. Direct input of this hydraulic gradient equation is possible; subsequently, the local hydraulic gradient distributions can be fixed, affected both by seepage length and hydraulic head loss. In this study, the tentative seepage length $d z^{\prime}$ and the tentative hydraulic head loss $d h^{\prime}$ are introduced to present the hydraulic gradient distribution, because changing one parameter is simpler. Equation (16) represents the ratio of $\left.d z\right|_{n=1}$ to $\left.d z\right|_{n=2}$, and the ratio of $\left.d h\right|_{n=1}$ to $\left.d h\right|_{n=2}$. The equation is initially simulated when the hydraulic gradient is constant between the two points as shown in the blue line (if constant) depicted in Fig. $5 \mathrm{a}$ and $\mathrm{b}$. The seepage length and the hydraulic head loss are equal between points 1 and 2, respectively, when $\alpha_{z}=1$ in Eq. (16). If not, the total tentative seepage length must be the same as the true seepage length, and the coefficient of $\beta_{L}$ is determined in Eq. (19). Therefore, the entire real seepage length is not affected, and the local hydraulic distributions are calculated using this treatment. Modified seepage length is represented from Eqs. (17) to (19),

$$
\frac{\left.d z\right|_{n=1}}{\left.d z\right|_{n=2}}=\frac{\left.d h\right|_{n=1}}{\left.d h\right|_{n=2}}=\left.\alpha_{z} \Rightarrow \frac{d h}{d z}\right|_{n=1}=\left.\frac{d h}{d z}\right|_{n=2},
$$

$$
\left(\frac{d h}{d z}\right)^{\prime}=\frac{d h}{d z^{\prime}}
$$

$\left.d z^{\prime}\right|_{n=1}=\left.\frac{\beta_{L}}{K_{t}+1} d z\right|_{n=1}$

$\left.d z^{\prime}\right|_{n=2}=\left.\frac{\beta_{L} K_{t}}{K_{t}+1} d z\right|_{n=2}$,

$\beta_{L}=\frac{\left(\alpha_{z}+1\right)\left(K_{t}+1\right)}{\alpha_{z}+K_{t}}$

The schematic representation of a tentative and actual seepage length is shown in Fig. 7 a, based on the case of right side of Fig. 5 a. The estimated hydraulic gradient in Fig. 5 is replaced by a modified one in Fig. 7. The modification is influenced by the cells adjacent to each other in the numerical analysis. Changing the permeability corresponding to the velocity instead of each cell's hydraulic gradient is easier, but the hydraulic gradient is not accurately calculated thus. In addition, changing the permeability coefficient sometimes does not entail any physical meaning for the given situation. Tentative head loss can also be applied as shown in Eqs. (20) and (21) under Eq. (15). The coefficient of $\gamma_{h}$ in Eq. (22) is established for maintaining the total modified head loss identical, compared to the original head loss through the points. The schematic is depicted in Fig. 7b, which has the same correction as Fig. 7a, 
$\left(\frac{d h}{d z}\right)^{\prime}=\frac{d h^{\prime}}{d z}$,

$\left.d h^{\prime}\right|_{n=1}=\left.\frac{\gamma_{h} K_{t}}{K_{t}+1} d h\right|_{n=1}$,

$\left.d h^{\prime}\right|_{n=2}=\left.\frac{\gamma_{h}}{K_{t}+1} d h\right|_{n=2}$,

$\gamma_{h}=\frac{\left(\alpha_{z}+1\right)\left(K_{t}+1\right)}{\alpha_{z} K_{t}+1}$

The divergence formula and the actual calculation step have not yet been confirmed in the case of both tentative seepage length and tentative head loss. The inconsistent zone where the modification is accomplished must be determined at an initial condition. The basic concept is mentioned in the study; the actual working of this method should be verified in the next step. It is not clear what is better-the tentative seepage length or the tentative head loss. In the actual analysis, fixing all the cells considering tentative values without any rupture might be difficult. Tentative head loss may be influenced by the seepage flow conditions while the tentative length may not be affected as much; the hydraulic gradient varies every moment with the seepage flow in unsaturated soil. The combination of the tentative length and tentative head loss should be also considered. This modification can be used in the range defined by $f_{r} \geq 0$ in Eq. (8); it is transformed by the use of Eq. (23b),

$K_{t}<1$, if $\theta_{1}>\theta_{2}$,

$K_{t}>1$, if $\theta_{2}>\theta_{1}$

This study calculated the simplest, one-dimensional seepage flow through the vertical $z$ direction. Its extension to the $x$ and $y$ directions is not an issue. The study does not solve the exact equation, but it can be derived fundamentally from Eq. (2) and Darcy's law as follows, and the same criterion of Eq. (6) can be applied,

$v_{n, x}=\frac{k_{x}{ }^{s} K_{r}\left(\theta_{n}\right)}{\theta_{n}} \frac{d h}{d x}$

$v_{n, y}=\frac{k_{y}{ }^{s} K_{r}\left(\theta_{n}\right)}{\theta_{n}} \frac{d h}{d y}$

where $k_{x}$ and $k_{y}$ represent the permeability coefficient of the $x$ and $y$ directions in Eq. (24). Under the simple calculations, $k_{x}$ and $k_{y}$ are regarded as the equal to $k_{z}$ : permeability coefficient of the $z$ direction. In geotechnical engineering, the permeability coefficient of the $z$ direction is commonly measured experimentally. The concern about the anisotropy of the seepage direction is discussed in previous studies; horizontal permeability is generally larger than the vertical one, e.g., Mualem (1984). The proposed tentative seepage length or the hydraulic head loss from Eqs. (16) to (22) can be similarly applied to the $x$ and $y$ directions.

\section{Simple evaluation of the proposed method}

The implementation for the numerical analysis should deal with many problems as previously mentioned, but the simple evaluation of the specific values calculated by this method is described in this chapter. The van Genuchten model (cited from van Genuchten, 1980) is applied to calculate hydraulic conductivity as shown in Eqs. (25a) and (25b), where $\theta_{r}$ is the residual water content, and $l, m, n, \alpha$ are the model parameters. This study applies $l=0.5$ and $m=1-1 / n$. The other substituted values are shown in Table 2, cited from Sakai and Toride (2009),

\section{a tentative seepage length}

\section{b tentative hydraulic head loss}

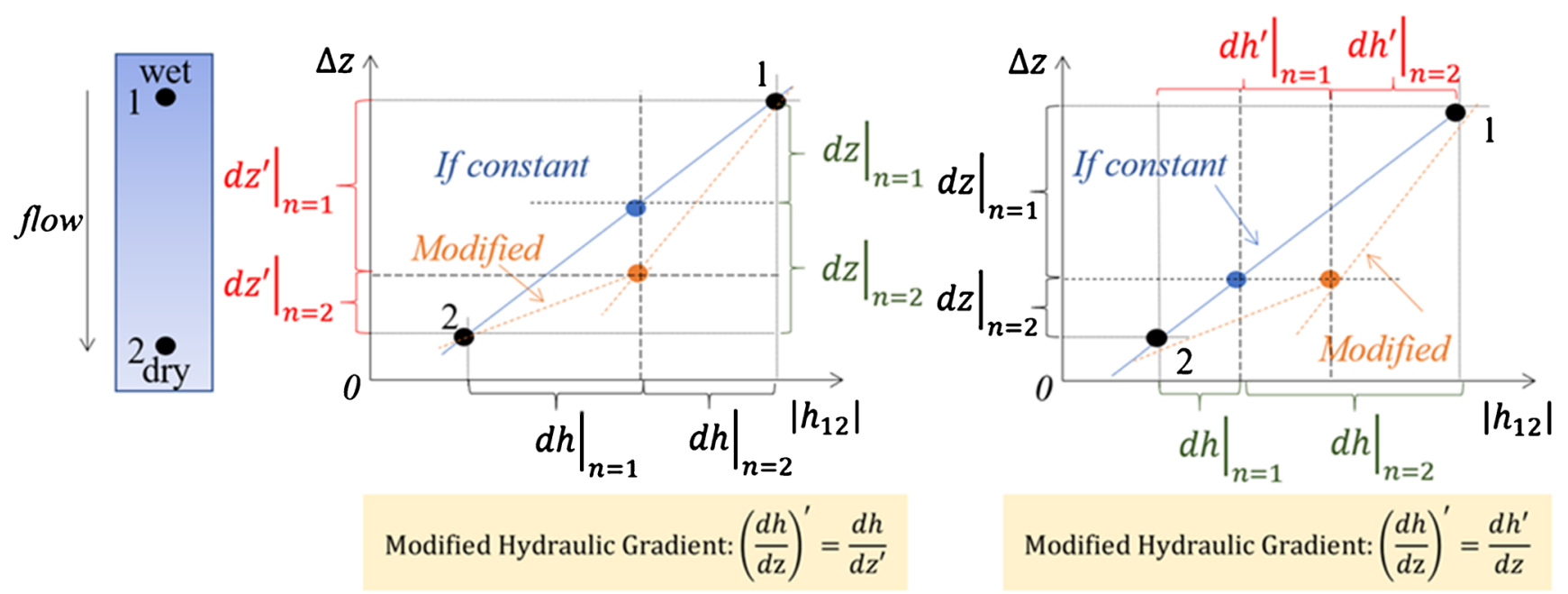

Fig. 7 a Concept of tentative seepage length, referring to right of Fig. 5 a. b Concept of tentative hydraulic head loss, referring to right of Fig. 5 a 
$S_{e}=\frac{\theta-\theta_{r}}{\theta_{s}-\theta_{r}}=\left(1+|\alpha \psi|^{n}\right)^{-m}$

$K\left(S_{e}\right)=K_{s} S_{e}^{l}\left[1-\left(1-S_{e}^{1 / m}\right)^{m}\right]^{2}$

The procedure is described as follows. First, as this method simulates the local distributions of water content in unsaturated soil, the volume of water content difference between point 1 and point 2 is fixed. The case considers that point 1 has lower water content than point 2 , being depicted by the concrete values in Table 3 . Then, hydraulic conductivity is calculated by the van Genuchten model, and the applicability of the method is confirmed by Eq. (4b). $f_{r}$ is arranged to Eq. (23b). The case that $\theta_{2}>\theta_{1}$ is simulated and Eq. (23b) is installed for judging the applicability. Note that Eq. (4b) can also be installed for judging the applicability.

Finally, the coefficient of $K_{t}$, shown in Eqs. (14) and (17c) is calculated. $K_{t}$ governs the ratio of hydraulic gradient of point 1 and point 2 and tentative seepage length or hydraulic head loss can be calculated when the other specific values are determined. Therefore, the evaluation of this study calculated the value of $K_{t}$. It is noted that the judgement of consistent or inconsistent condition by Eq. (6) is first required. It is estimated that the ground condition is already judged as the inconsistent condition. The criterion is determined by the ground and penetration condition on site, experiments, and numerical analysis, which are very complex and various future case studies are required.

The results are shown in Figs. 8 and 9. For the van Genuchten model, all of the cases in Table 2 satisfy Eq. (23b); the evaluation method of the local hydraulic gradient can be applied to every material in the study. As mentioned in the prior chapter, smaller water content has a lower possibility of not satisfying the applicability. This paper does not discuss whether the van Genuchten model mathematically has the possibility of not satisfying $f_{r}$ and Eq. (23b). As a minimum, standard materials and parameters given in Table 2 satisfy the equations.

The calculated values of $K_{t}$ are depicted in Figs. 8 and 9. $K_{t}$ decreases with the increase of water content, indicating that

Table 2 Parameters for soils with van Genuchten model, cited from Sakai and Toride

\begin{tabular}{llllll}
\hline Material & $\theta_{r}\left(\mathrm{~cm}^{3} \mathrm{~cm}^{-3}\right)$ & $\theta_{s}\left(\mathrm{~cm}^{3} \mathrm{~cm}^{-3}\right)$ & $\alpha\left(\mathrm{cm}^{-1}\right)$ & $n(-)$ & $K_{s}\left(\mathrm{~cm} \mathrm{~d}^{-1}\right)$ \\
\hline Loamy sand & 0.057 & 0.41 & 0.124 & 2.28 & 350.2 \\
Silt & 0.034 & 0.46 & 0.016 & 1.37 & 6 \\
Silty clay & 0.07 & 0.36 & 0.005 & 1.09 & 0.48 \\
Sand & 0.045 & 0.43 & 0.145 & 2.68 & 712.8 \\
\hline
\end{tabular}

Cited from Sakai and Toride (2009) and the forms are partially arranged the local hydraulic gradient distribution is reduced with higher water content. Conversely, $K_{t}$ slightly increases again in the saturation range vicinity. The value of $K_{t}$ is approximately 1.1-3.0 when the water contents gap between two points is 0.01 except SC1. The value is not excessively large for the existing numerical analysis, being able to be installed as the local hydraulic gradient distribution. The $K_{t}$ of $\mathrm{SC} 1$ has a larger value than other materials, especially in lower water content. $K_{t}=1115.7$ at $\theta_{1}=0.01$, and Fig. 8 does not depict the point in the plotting range. It is suggested that $K_{r}(\theta)$ is very small when the soil has very low water content or consists of finer materials, which leads the significant difference between $K_{r}\left(\theta_{1}\right)$ and $K_{r}\left(\theta_{2}\right)$. One solution for the phenomenon is changing the water content gaps among two points. Figure 9 represents $K_{t}$ on LS2, showing the effect of the variations of the gaps of $\theta_{1}$ and $\theta_{2}$ on $K_{t}$. It reveals that the divergence of $K_{t}$ disappears by setting the small gaps. Namely, small size meshes are required when $K_{t}$ is extremely large for numerical analysis, as constitutive calculations between the two points are difficult. As mentioned in the previous chapter, evaluating details of these effects and practical application to the numerical analysis are to be included in the future works. The research describes the momentary phenomenon, and the modification of local hydraulic gradient distribution has the possibility to change the seepage situations with the progression of time.

Notably, this study applied the van Genuchten model as an example and the results are varied by the settings of the parameters of hydraulic conductivity and water content. The ranges close to dry condition or saturation have some unique behaviors and there are several studies in this regard, e.g., Schaap and van Genuchten (2006).

\section{Conclusions}

A simple criterion under a one-dimensional condition is proposed in this study; when $f_{r}>0$ and $|\mathrm{h}-\Delta \mathrm{z}| \geq \Delta \psi$ are fulfilled, the condition is regarded as consistent to the existing theories of unsaturated soil. This criterion can easily evaluate the flow under conditions other than analytical conditions and can also be immediately applied under in situ conditions. For

Table 3 Calculated cases

\begin{tabular}{llll}
\hline Case & Material & $\theta_{1}\left(\mathrm{~cm}^{3} \mathrm{~cm}^{-3}\right)$ & $\theta_{2}\left(\mathrm{~cm}^{3} \mathrm{~cm}^{-3}\right)$ \\
\hline LS1 & Loamy sand & $0.1,0.2,0.3,0.4$ & $\theta_{1}+0.01$ \\
Si1 & Silt & $0.1,0.2,0.3,0.4$ & $\theta_{1}+0.01$ \\
SC1 & Silty clay & $0.1,0.2,0.3$ & $\theta_{1}+0.01$ \\
Sn1 & Sand & $0.1,0.2,0.3,0.4$ & $\theta_{1}+0.01$ \\
LS2 & Loamy sand & 0.07 & $\theta_{1}+0.001,0.002,0.005,0.01$ \\
\hline
\end{tabular}


Fig. $8 K_{t}$ on LS1, Si1, SC1, and $\mathrm{Sn} 1$

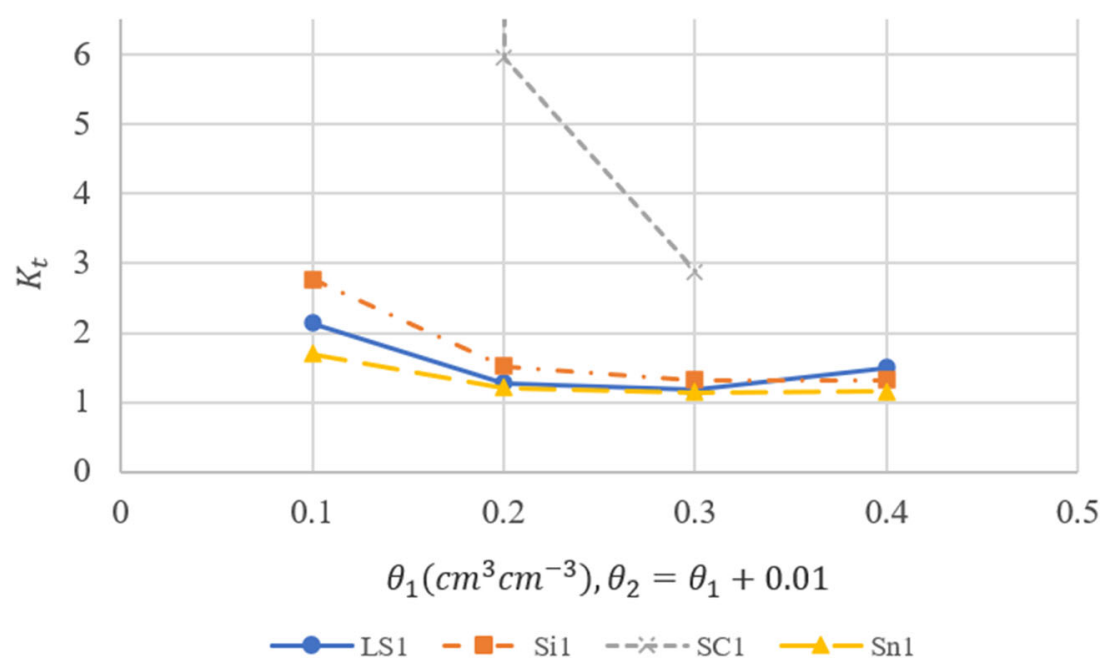

example, $\Delta \psi$ can be measured using a tensiometer; the water content can also be measured in situ. Then, hydraulic head can be evaluated from the inlet and outlet conditions. By the combination of these indices, consistent or inconsistent condition is judged. For both the consistent and inconsistent conditions, when the value is far away from the piezometric head line, the continuous flow is not generated, and it is estimated that the ground is in a peculiar condition. In contrast, the flow can be controlled by varying water content distributions and the flow direction in the ground.

Under inconsistent conditions, the local hydraulic gradient distribution that solves the inconsistency may be imposed. The modification method is proposed as the tentative seepage length and hydraulic gradient. The discretization and installation for the numerical analysis are included in the scope of future studies. This equation solves a momentary situation, but gradual water content change with time progression needs to be considered to solve sequential situations. The degree of modification is small, not influencing the entire ground seepage situation, if the inconsistent area is narrow. Conversely, when the inconsistent area is wide, it is assumed to have an influence on the ground seepage conditions. As a result of installation of the proposed modification method to the Mualem-van Genutchen model, the finer material has a large gradient, whereas sand has a smaller one. The modification will contribute to solve the local and concentrate seepage without using investigated data. Consistent vicinity of the piezometric head line should also be discussed in the future. Although the consistent condition does not have obvious failures related to the well-known theories, the modification is required when the value deviates significantly from the piezometric head line during the numerical analysis. Please note that the proposed method leads the minimum modification, having a risk of underestimation of the inconsistency. In addition, when the water content ranges close to the dry conditions or saturation, the application of the proposed method should be discussed; various models are not always suitable at those ranges.

This criterion is fulfilled under the uniform ground condition, but the actual ground generally consists of various layers.

Fig. $9 K_{t}$ on LS2

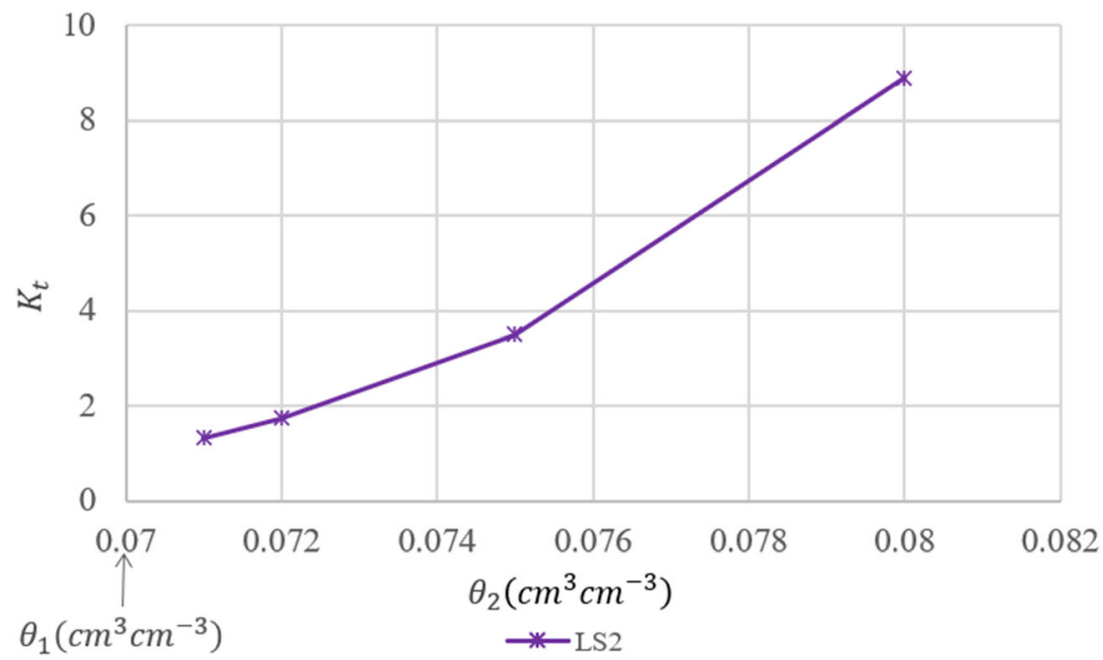


The ground seepage with multiple layers has several problems, and there are many related investigations and experiments, e.g., Abdulaziz and Faid (2015); Li and Leao (2018). When the ground is not uniform and the material properties are different between the two points, the difference of properties primarily governs velocity, pressure head, and magnitude, positive and negative of the term $v_{1}^{2}-v_{2}^{2}$. Alternatively, when the material properties of layers are similar or slightly different, the velocity term $v_{1}^{2}-v_{2}^{2}$ is changed by the water content, the proposed criterion can be applied, but the details are to be explored in future study.

Funding information Publication and proof-reading fees are supported by the Management Expenses Grants of Faculty of Life and Environmental Science, Shimane University.

Availability of data and material Not applicable.

Code Availability Not applicable.

\section{Compliance with ethical standards}

Conflict of interest The author declares that she has no conflict of interest.

Notations $P$, fluid pressure $\left[\mathrm{M} \mathrm{L}^{-} 1 \mathrm{~T}^{-} 2\right] ; g$, gravity [LT 2$] ; v$, fluid velocity [LT 1$] ; \rho$, fluid density $\left[\mathrm{ML}^{-} 3\right] ; z$, height $[\mathrm{L}] ; h$, hydraulic head $[\mathrm{L}] ; \psi$, pressure head $[\mathrm{L}] ; \theta$, water content $\left[\mathrm{L}^{3} \mathrm{~L}^{-3}\right] ; \theta_{s}$, volumetric water content at saturation $\left[\mathrm{L}^{3} \mathrm{~L}^{-3}\right] ; \theta_{r}$, residual volumetric water content $\left[\mathrm{L}^{3} \mathrm{~L}\right.$ $\left.{ }^{-3}\right] ; S_{e}$, effective degree of saturation [-]; $K_{r}$, relative permeability [LT 1$]$; $k^{s}$, coefficient of permeability at saturation $\left[\mathrm{LT}^{-} 1\right] ; K_{t}$, function of the modification of hydraulic gradient [-]; $f_{K}$, ratio of relative permeability to water content $\left[\mathrm{L}^{3} \mathrm{~T}^{-1} \mathrm{~L}^{-2}\right] ; f_{r}$, function of the applicability of the criterion $\left[\mathrm{L} 6 \mathrm{~T}^{-1} \mathrm{~L}^{-5}\right] ; \alpha_{z}$, ratio of the mesh lengths of one point to the neighbor point; $\beta_{L}$, coefficient for the tentative seepage length [-]; $\gamma_{h}$, coefficient for the tentative hydraulic head [-]

Open Access This article is licensed under a Creative Commons Attribution 4.0 International License, which permits use, sharing, adaptation, distribution and reproduction in any medium or format, as long as you give appropriate credit to the original author(s) and the source, provide a link to the Creative Commons licence, and indicate if changes were made. The images or other third party material in this article are included in the article's Creative Commons licence, unless indicated otherwise in a credit line to the material. If material is not included in the article's Creative Commons licence and your intended use is not permitted by statutory regulation or exceeds the permitted use, you will need to obtain permission directly from the copyright holder. To view a copy of this licence, visit http://creativecommons.org/licenses/by/4.0/.

\section{References}

Abaqus analysis user guide 6.14, 2.8 .4 (2020) Continuity statement for the liquid wetting phase ina porous medium: http://ivt-abaqusdoc. ivt.ntnu.no:2080/v6.14/books/stm/default.htm (acceced on July 7th, 2020)

Abdulaziz AM, Faid AM (2015) Evaluation of the groundwater resources potential of Siwa Oasis using three-dimensional multilayer groundwater flow model, Mersa Matruh Governorate, Egypt. Arab J Geosci 8:659-675. https://doi.org/10.1007/s12517-013-1199-4

Baecher GB and Christian JT (2003) Reliability and statistics in geotechnical engineering, John Wiley \& Sons, Inc. ISBN-13: 9780471498339

Bear J (1972) Dynamics of fluids in porous media. Elsevier, New York ISBN-13: 978-0486656755

Brooks RH, Corey AT (1966) Properties of porous media affecting fluid flow. J Irrig Drain Div 92(2):61-88

Bui HH, Nguyen GD (2017) A coupled fluid-solid SPH approach to modelling flow through deformable porous media. Int J Solids Struct 125:244-264. https://doi.org/10.1016/j.ijsolstr.2017.06.022

Childs EC and Collis-George N (1950) The permeability of porous maerialst. Proceedings of the Royal Society of London. Series A, Mathematical and Physical Sciences 201:392-405. Royal Society, London. DOI: https://doi.org/10.1098/rspa.1950.0068

Chong SK, Green RE, Ahuja LR (1981) Simple in situ determination of hydraulic conductivity of power function descriptions of drainage. Water Resour Res 17:1109-1114. https://doi.org/10.1029/ WR017i004p01109

Darcy H (1856) Les Fontaines Publiques de la Ville de Dijon. Dalmont, Paris

Emeka AE, Chukwuemeka AJ, Okwudili MB (2018) Deformation behaviour of erodible soil stabilized with cement and quarry dust. Emerg Sci J 2(6):383-387. https://doi.org/10.28991/esj-201801157

Fazlina MIS, Azhar ATS, Aziman M (2018) Design, operation and construction of a large rainfall simulator for the field study on acidic barren slope. Civil Eng J 6(1):1851-1857. https://doi.org/10.28991/ cej-2020-03091461

Finlyson BA (1972) The method of weighted residuals and variational principles with application in fluid mechanics, heat and mass transfer, Academic Press. ISBN-13: 978-0122570506

Fish J and Belytschko T (2007) A first course of finite elements, John Wiley \& Sons, Inc. ISBN-13: 978-0470035801

Fredlund DG, Rahardjo H, and Fredlund MD (2012) Unsaturated soil mechanics in engineering practice, John Wiley \& Sons, Inc. ISBN-13: 978-1118133590

Ho-Le K (1988) Finite element mesh generation methods: a review and classification. Computer-Aided Des 20:27-38. https://doi.org/10. 1016/0010-4485(88)90138-8

Hughes TJR (1987) The finite element method linear static and dynamic finite element analysis, Dover Publications, Inc. ISBN-13: 9780486411811

Huyakorn PS, Thomas SD, Thompson BM (1984) Techniques for making finite elements competitive in modeling flow in variably saturated porous media. Water Resour Res 20:1099-1115. https://doi.org/ 10.1029/WR020i008p01099

Huyakorn PS, Springer EP, Guvanasen V, Wadsworth TD (1986) A three-dimensional finite-element model for simulating water flow in variably saturated porous media. Water Resour Res 22:1790 1808. https://doi.org/10.1029/WR022i013p01790

Jones A (1971) Soil piping, and stream channel initiation. Water Resour Res 7:602-610. https://doi.org/10.1029/WR007i003p00602

Kassou F, Bouziyane JB, Ghafiri A, Sabihi A (2020) Slope stability of embankments on soft soil improved with vertical drains. Civil Eng J 6(1):164-173. https://doi.org/10.28991/cej-2020-03091461

Klute A (1965) Laboratory measurement of hydraulic conductivity of unsaturated soil, Methods of Soil Analysis, Monogram 9(1), American Society of Agronomy, Madison, pp 253-261. DOI: https://doi.org/10.2134/agronmonogr9.1.c16

Li J, Leao TF (2018) Application of nor sand constitutive model in a highway fill embankment slope stability failure study. Civil Eng J 4(10):2252-2263. https://doi.org/10.28991/cej-03091155 
McCord JT (1991) Application of second-type boundaries in unsaturated flow modeling. Water Resour Res 27:3257-3260. https://doi.org/10. 1029/91WR02158

Moffat R, Fannin J, Garner SJ (2011) Spatial and temporal progression of internal erosion in cohesionless soil. Can Geotech J 48:399-412. https://doi.org/10.1139/T10-071

Mohammad P, Martin JB (2005) Three-dimensional mixed-wet random pore-scale network modeling of two- and three-phase flow in porous media I. Model description. Phys Review E 71:026301. https://doi. org/10.1103/PhysRevE.71.026301

Mualem Y (1976) A new model for predicting the hydraulic conductivity of unsaturated porous media. Water Resour Res 12:513-522. https:// doi.org/10.1029/WR012i003p00513

Mualem Y (1984) Anisotropy of unsaturated soils. Soil Sci Soc Am J 48: 505-509. https://doi.org/10.2136/sssaj 1984 . $03615995004800030007 \mathrm{x}$

Richard LA, Moore DC (1952) Influence of capillary conductivity and depth of wetting on moisture retention in soil. Trans Am Geophys Union 33:531-540. https://doi.org/10.1029/TR033i004p00531

Richards LA (1931) Capillary conduction of liquids through porous mediums. Physics 1:318-333. https://doi.org/10.1063/1.1745010

Sakai M, Toride N (2009) Hydraulic property models for water retention and unsaturated hydraulic conductivity. J Jpn Soc Soil Physics 111: 61-73 in Japanese. J-GLOBAL ID: 200902274377802386

Schaap MG, van Genuchten MT (2006) A modified Mualem-van Genuchten formulation for improved description of the hydraulic conductivity near saturation. Vadose Zone J 5:27-34. https://doi. org/10.2136/vzj2005.0005

Schindler U, Durner W, von Unold G, Muller L (2010) Evaporation method for measuring unsaturated hydraulic properties of soils: extending the measurement range. Soil Sci Soc Am J 74:1071-1083. https://doi.org/10.2136/sssaj2008.0358

Scott BJ, Dani O (1999) Microgravity effects on water flow and distribution in unsaturated porous media: analysis of flight experiments. Water Resour Res 35:929-942. https://doi.org/10.1029/ 1998WR900091
Shishido K, Hashida H, Inazumi S, Soralump S (2018) Penetration behaviour of chemical grouting considering ground uncertainty. Int J Geomate 14:22-27. https://doi.org/10.21660/2018.45.57186

Sisson JB (1987) Drainage from layered field soils: fixed gradient models. Water Resour Res 23:2071-2075. https://doi.org/10.1029/ WR023i011p02071

Tao H, Tao J (2017) Quantitative analysis of piping erosion micromechanisms with coupled CFD and DEM method. Acta Geotech 12:573-592. https://doi.org/10.1007/s11440-016-0516-y

Todd DK (1959) Ground water hydrogy, John Willey \& Sons, Inc.

Tu XB, Kwong AKL, Dai EC, Tham LG, Min H (2009) Field monitoring of rainfall infiltration in a loess slope and analysis of failure mechanism of rainfall-induced landslides. Eng Geol 105:134-150. https://doi.org/10.1016/j.enggeo.2008.11.011

Van Beek VM, Van Essen HM, Vandenboer K, Bezuijen A (2015) Developments in modelling of backward erosion piping. Geotechnique 65:740-754. https://doi.org/10.1680/geot.14.P.119

Van Genuchten MT (1980) A closed-form equation for predicting the hydraulic conductivity of unsaturated soils. Soil Sci Soc Am J 44: $892-898$. https://doi.org/10.2136/ss saj 1980 . $03615995004400050002 x$

Wagner BJ, Gorelick SM (1989) Reliable aquifer remediation in the presence of spatially variable hydraulic conductivity: from data to design. Water Resour Res 25(10):2211-2225. https://doi.org/10. 1029/WR025i010p02211

Whitaker S (1986) Flow in porous media I: a theoretical derivation of Darcy's law. Transp Porous Media 1:3-25. https://doi.org/10.1007/ BF01036523

Wulong H, Guofeng L, Xiaoxian Z (2018) A pore-scale model for simulating water flow in unsaturated soil. Microfluid Nanofluid 22:71. https://doi.org/10.1007/s10404-018-2090-0

Ye X, Qiu J, Zhang C, Liang R, Wang B (2009) A finite element-based heuristic estimation of local preform permeability for resin transfer molding. Transp Porous Media 76:247-263. https://doi.org/10. 1007/s11242-008-9245-5 